\title{
Seismic waves in 3-D: from mantle asymmetries to reliable seismic hazard assessment
}

\author{
Giuliano F. Panza $\cdot$ Fabio Romanelli
}

Received: 8 August 2013/ Accepted: 16 April 2014/Published online: 4 October 2014

(C) The Seismological Society of China, Institute of Geophysics, China Earthquake Administration and Springer-Verlag Berlin Heidelberg 2014

\begin{abstract}
A global cross-section of the Earth parallel to the tectonic equator (TE) path, the great circle representing the equator of net lithosphere rotation, shows a difference in shear wave velocities between the western and eastern flanks of the three major oceanic rift basins. The lowvelocity layer in the upper asthenosphere, at a depth range of 120 to $200 \mathrm{~km}$, is assumed to represent the decoupling between the lithosphere and the underlying mantle. Along the TE-perturbed (TE-pert) path, a ubiquitous LVZ, about $1,000-\mathrm{km}$-wide and 100-km-thick, occurs in the asthenosphere. The existence of the TE-pert is a necessary prerequisite for the existence of a continuous global flow within the Earth. Ground-shaking scenarios were constructed using a scenario-based method for seismic hazard analysis (NDSHA), using realistic and duly validated synthetic time series, and generating a data bank of several thousands of seismograms that account for source, propagation, and site effects. Accordingly, with basic selforganized criticality concepts, NDSHA permits the integration of available information provided by the most updated seismological, geological, geophysical, and
\end{abstract}

G. F. Panza $(\varangle) \cdot$ F. Romanelli

Department of Mathematics and Geosciences, University of Trieste, Via Weiss 4, 34127 Trieste, Italy

e-mail:panza@units.it

\section{G. F. Panza - F. Romanelli}

International Center for Theoretical Physics, SAND group,

Via Weiss 4, 34127 Trieste, Italy

G. F. Panza

International Seismic Safety Organization, ISSO,

http://www.issoquake.org/

G. F. Panza

IG-CEA, Beijing, China geotechnical databases for the site of interest, as well as advanced physical modeling techniques, to provide a reliable and robust background for the development of a design basis for cultural heritage and civil infrastructures. Estimates of seismic hazard obtained using the NDSHA and standard probabilistic approaches are compared for the Italian territory, and a case-study is discussed. In order to enable a reliable estimation of the ground motion response to an earthquake, three-dimensional velocity models have to be considered, resulting in a new, very efficient, analytical procedure for computing the broadband seismic wave-field in a 3-D anelastic Earth model.

Keywords 3D Earth $\cdot$ Lithosphere $\cdot$ Mantle $\cdot$ Seismic hazard · Synthetic seismograms

\section{Introduction}

In 1678, Athanasius Kircher depicted the most advanced thinking about the internal structure of our planet (Kircher 1678). He postulated that the Earth contained a giant, fiery inferno, coincident with our current understanding of the Earth's molten outer core. The fires, through a complex network of channels, fissures, and subsidiary bodies distributed through the interior, supplied heat to the surface water that seeped in from the ocean and gave rise to hot springs (Fig. 1, upper). Where tongues of fire (molten material) came close to Earth's surface, volcanoes formed, and this idea reflects a pioneering awareness of volcanoes as a global phenomenon produced by a global process, rather than the purely localized product of wind action upon deposits of combustible materials. Kircher's work played an important part in the dissemination of this notion. 

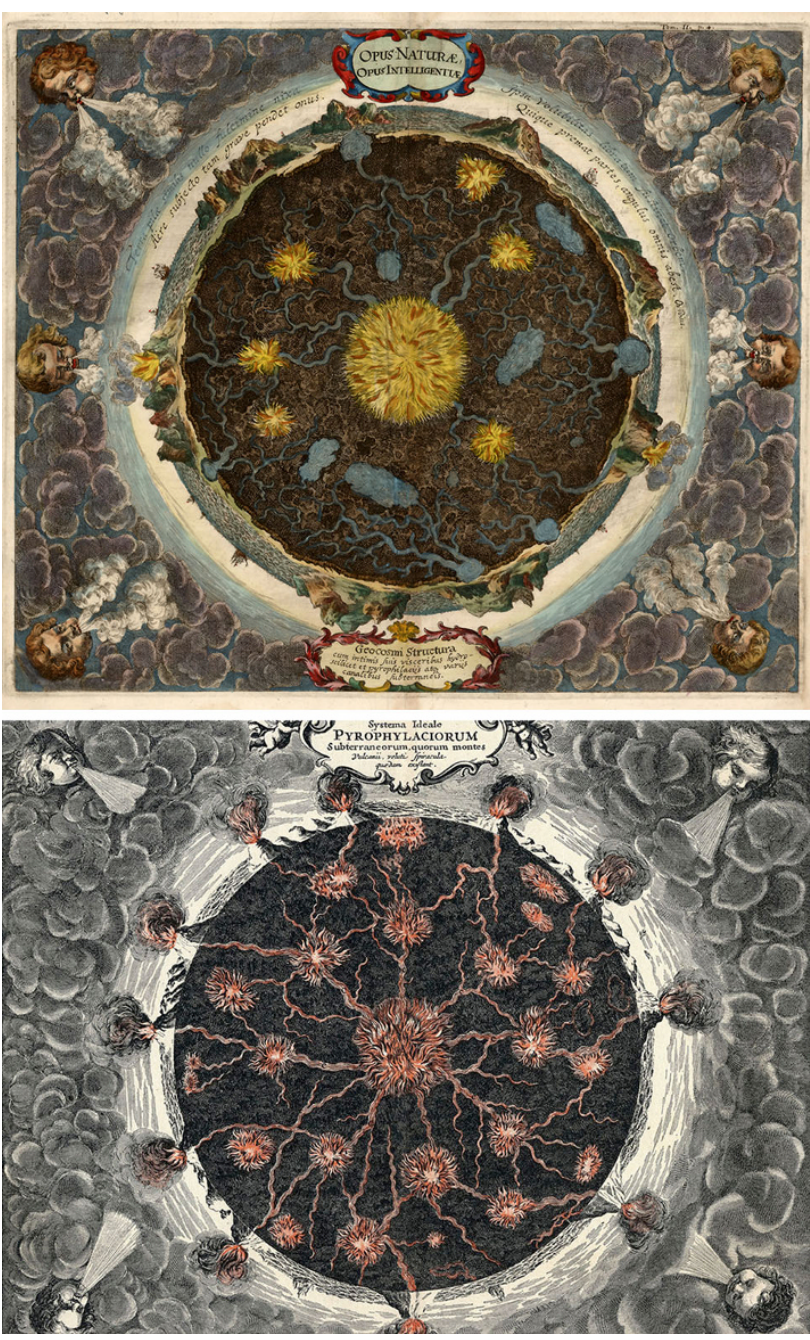

Fig. 1 The representation by Athanasius Kircher (1678) of the most advanced thinking of his day about the internal structure of our planet-note that, already at that time, the notion of non-uniqueness of the inverse problem was somehow perceived

As described in some detail in next section, low-velocity channels in the asthenosphere, where partially molten material is present, are indeed seen in shear wave velocity $\left(v_{\mathrm{s}}\right)$ sections along the tectonic equator (TE) (Panza et al. 2010). The declared purpose of the TE traced by Crespi et al. (2007) was to introduce, on the basis of geological evidence, the concept of tectonic mainstream and to prove its consistency with space geodesy data in order to propose a new, unified way to describe plate motions with respect to the underlying mantle. Accordingly, plate kinematics is described based on constraints from both velocities from space geodesy and geological evidence. The analytical expressions of the reconstructed tectonic mainstreams are remarkably simple, involving only a first-order sinusoid in longitude that is quite close to the corresponding netrotation equators. It has been shown that global lithospheric rotation is physically feasible, although at variable velocities among the different plates (Scoppola et al. 2006). As a result, plate tectonics would occur with the combination of the behavior of a rotating planet under tidal torque, efficient internal convection, and lateral viscosity variations at the lithosphere-mantle interface. The viscosity of the upper asthenosphere is still unknown, but strong viscosity contrasts between the lithosphere and asthenosphere, compatible with experiments (Pollitz et al. 1998; Jin et al. 1994; O'Driscoll et al. 2009), are present at the top of the asthenosphere, allowing for the decoupling of the lithosphere (Doglioni et al. 2011). This observation is consistent with a global net rotation. The low-velocity layer in the upper asthenosphere, at a depth range of 120 to $200 \mathrm{~km}$, is assumed to represent the decoupling between the lithosphere and the underlying mantle, and a global circuit of partially molten material is seen along the TEperturbed path (TE-pert; see Fig. 2).

The lithospheric shell is the medium whose transfer function (still unknown) can be naturally responsible for the differences in shape between the TE and TE-pert. The LVZ does not need to be a continuous shell within the entire asthenosphere. The existence of a ubiquitous, toruslike, LVZ along TE-pert is sufficient to allow global circulation in the upper mantle, required by polarized plate tectonics.

$\mathrm{EPR}=$ East Pacific Rise;

$$
\text { MAR }=\text { Mid-Atlantic Ridge; IR }=\text { Indian Ridge }
$$

Such circulation is gravitationally quite stable, and in fact, most of the empirical relations linking density to seismic velocities imply that the two quantities vary consistently (i.e. density increases with increasing seismic velocity). However such a result contradicts, by definition, the inverse proportionality between velocity and density. Therefore, it is only reasonable to use densities obtained in such a way as starting values for the inversion of, say, Bouguer anomalies. Following this procedure, it has been shown in several cases that the LVZ does not correspond to a low-density zone, and thus, it is gravitationally stable (e.g. Brandmayr et al. 2011; Zhang et al. 2014).

There are several publications describing the presentday understanding of plate tectonics (e.g. Anderson 2007; Foulger 2010; Foulger et al. 2013; www.mantleplumes. org), which they consider an example of a self-organizing complex system of hierarchical blocks in a critical (SOC) state (Prigogine and Stengers 1984; Keilis-Borok and Soloviev 2003); the lithosphere and the underlying mantle therefore represent a SOC system open to external perturbations (e.g. Anderson 2002; Stern 2002). As a consequence, the seismicity follows the Gutenberg-Richter (GR) law only on a global scale, while this simple SOC relation does not hold when considering smaller regions of the Earth. The assumption, proven to be wrong, of the general 
TE
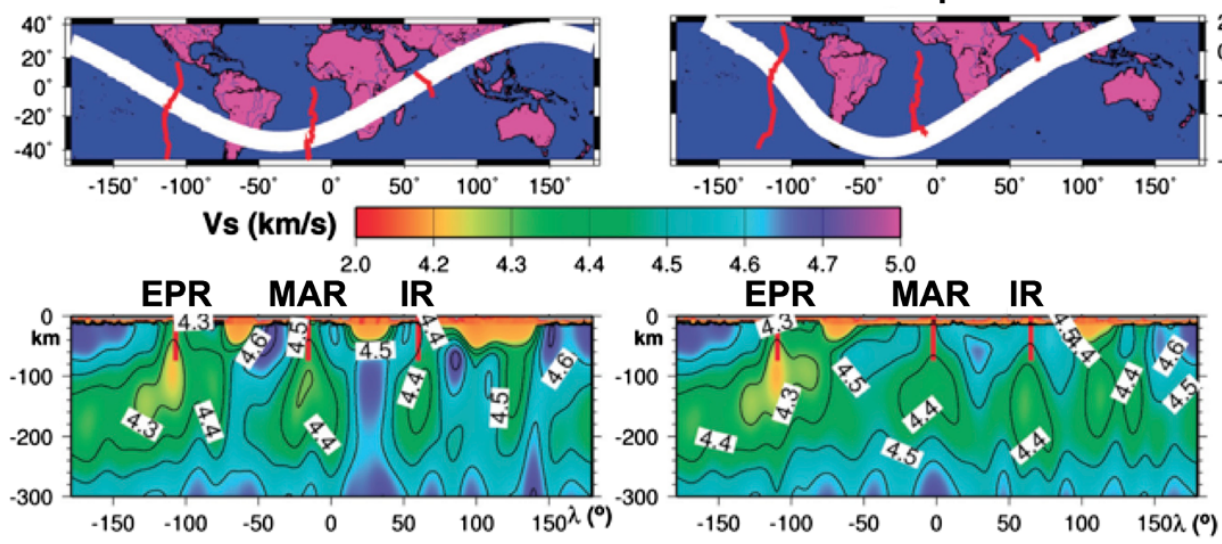

EPR=East Pacific Rise; MAR=Mid Atlantic Ridge; IR= Indian Ridge

Fig. 2 Shear wave velocity sections along the tectonic equator (TE) and a global circuit of partially molten material along the perturbed path (TE-pert), indicating the presence of partially molten material (lower part; modified from Panza et al. (2010))
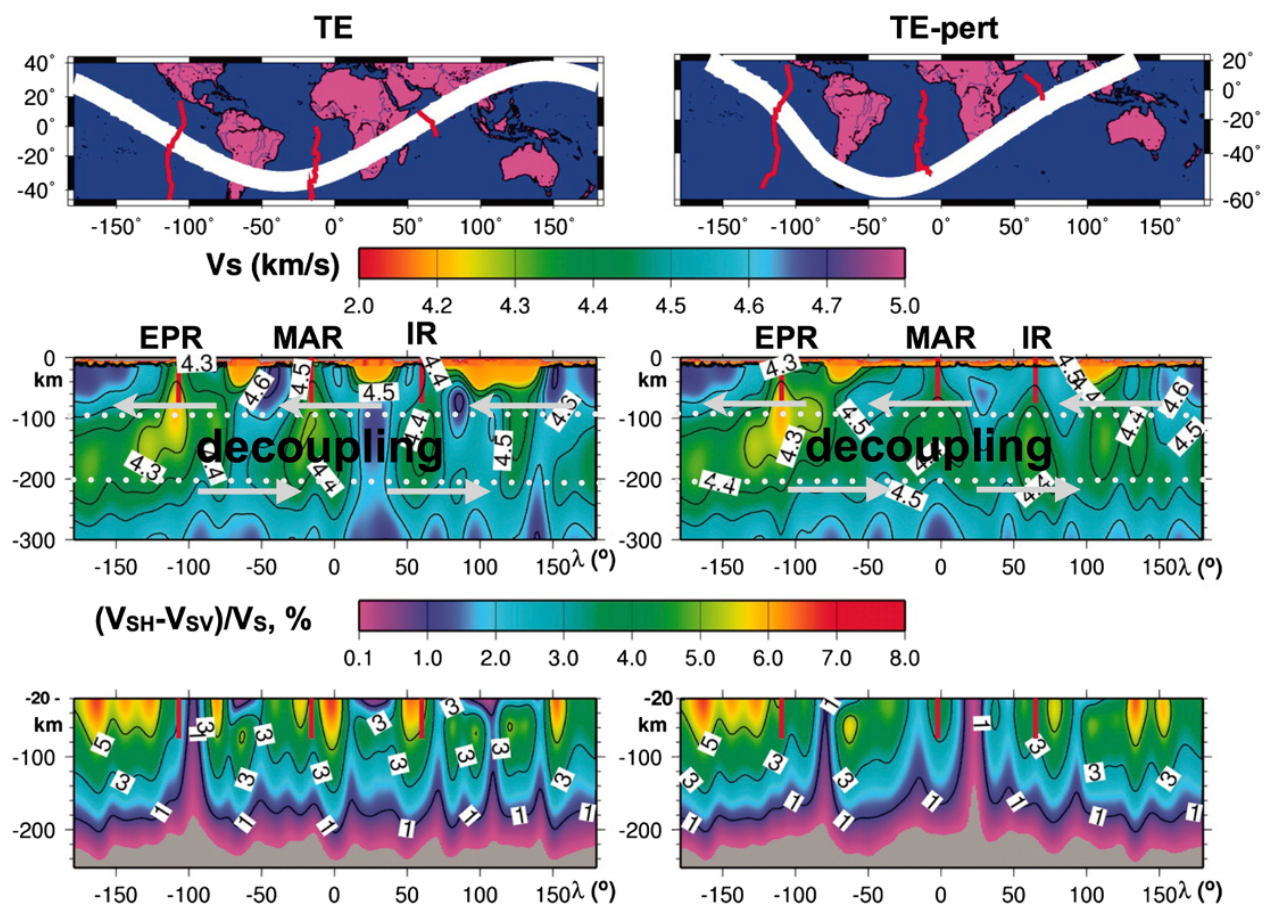

Fig. 3 Shear wave section along the tectonic equator (TE) and perturbed path (TE-pert) of the Earth. Generalized asymmetry is evident across oceanic ridges: lithosphere $(0-100 \mathrm{~km})$ on the western side of the rift has a higher velocity than on the eastern or northeastern side, whereas the upper asthenosphere (low-velocity layer, 100-200 km) has a slower velocity on the western side with respect to the conjugate counterpart. Red lines correspond to elements of the Eastern Pacific, Mid-Atlantic, and Indian Ridges. Radial anisotropy sections shown in the lower panels are without crust, since the crust is assumed to be isotropic. Vs is taken here as average of Vsv and Vsh (modified from Panza et al. 2010). Along the TE-pert, which is not a great circle, a ubiquitous LVZ, about 1,000-km-wide and 100-km-thick, occurs in the asthenosphere, where the most mobile mantle (LVZ) is located (decoupling layer). The arrows indicate the possible relative motion

(i.e. scale-invariant) validity of GR law is the basis of standard global and national seismic hazard assessment techniques.

In this paper, we present examples that demonstrate the great importance of reliable modeling tools for the propagation of elastic and anelastic waves within the Earth. A sample of the applicability of waveform modeling is supplied, ranging from deep studies of the physical properties of our planet to both reliable assessments of seismic hazard at the global and local scale and also seismic 


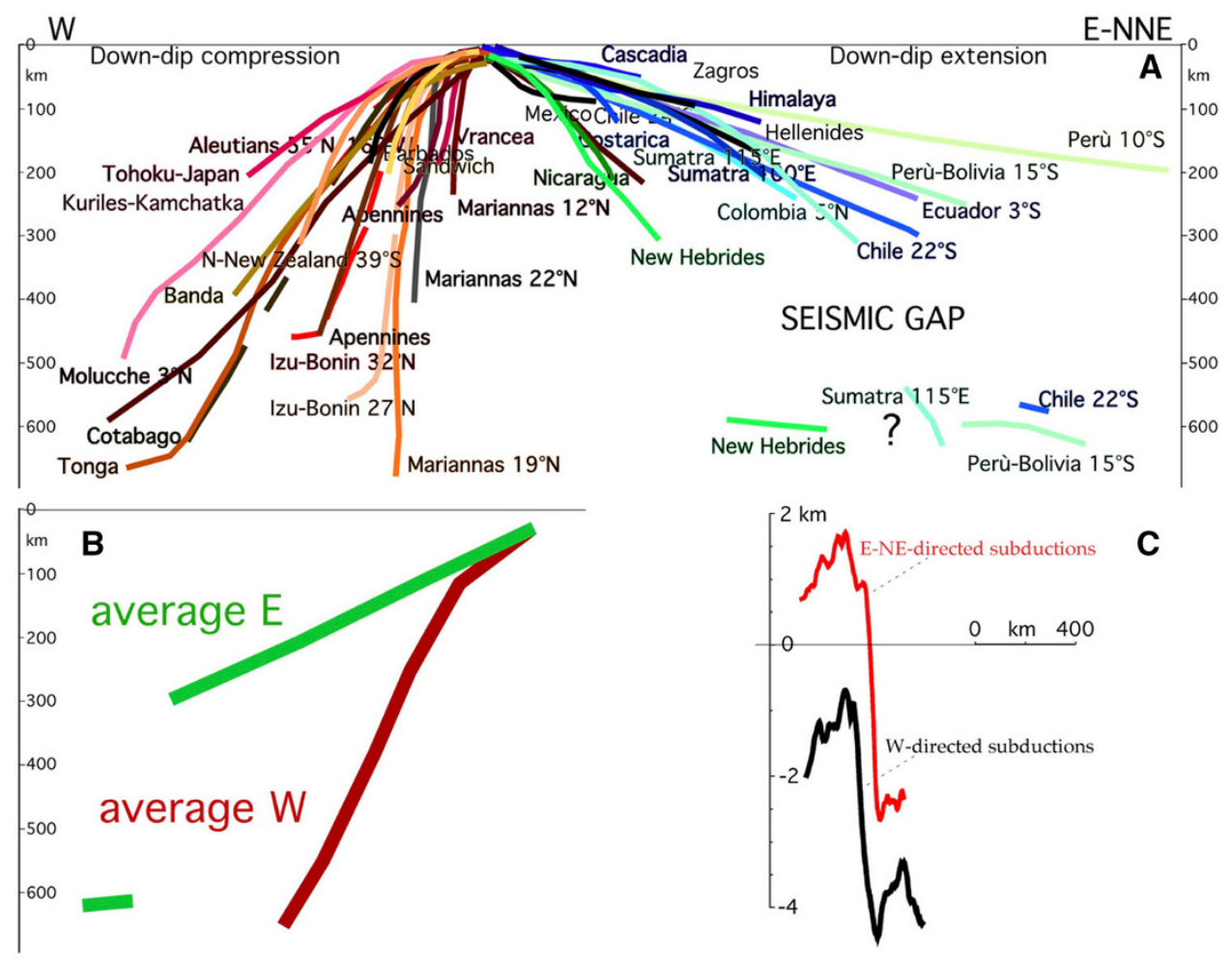

Fig. 4 Slab dip measured along cross-sections perpendicular to the trench of most subduction zones. The asymmetry is also marked by the seismic gap between around 300 and $550 \mathrm{~km}$, occurring only along the E- or NE-directed subduction zones, which are, in general, shorter than the W-directed slabs. The W-directed slabs are, on average, dipping $65.6^{\circ}$, whereas the average dip of the E- or NE-directed slabs is $27.1^{\circ}$ (from Riguzzi et al. 2010)

zonation and microzonation, providing fundamental information for the optimal retrofitting of existing infrastructures and for the development of new ones.

\section{Polarized plate tectonics}

While the superficial expression of oceanic ridges is apparently symmetric, their deeper roots may be asymmetric. Based on a surface-wave, tomographic, threedimensional model of the Earth's uppermost $300 \mathrm{~km}$ (Shapiro and Ritzwoller 2002; http://ciei.colorado.edu/ $\sim$ nshapiro/MODEL/), Panza et al. (2010) constructed a global cross-section along the path of the TE. TE, that forms an angle relative to the geographic equator, is the great circle that represents the equator of the net rotation of the lithosphere, close to that of the revolution plane of the moon.

Shear wave velocities indicate a difference between the western and eastern flanks of the three major oceanic rift basins (Pacific, Atlantic, and Indian ridges). In general, the western limbs have a faster velocity and thicker lithosphere relative to the eastern and northeastern limbs, whereas the upper asthenosphere has a higher velocity in the eastern limb than in the western limb. Along the TE-pert, a ubiquitous low-velocity zone (LVZ) about $1,000-\mathrm{km}$-wide and about 100-km-thick occurs in the asthenosphere, where the most mobile mantle (LVZ) is located (Fig. 3).

The existence of TE-pert is a necessary prerequisite for the existence of a continuous global flow within the Earth, the westward drift of the lithosphere relative to the underlying mantle, already evidenced by the strong asymmetry between E- (or NE-) directed and W- (or SW-) directed subduction zones (Fig. 4).

The reevaluation of the possibility that Earth's rotation contributes to plate tectonics shows that if a very-low viscosity layer is present in the upper asthenosphere, the horizontal component of the tidal oscillation and torque would be able to slowly shift the lithosphere relative to the mantle. This conclusion is supported by the following observations: (1) plates move along a westerly polarized flow that forms an angle relative to the equator, close to the revolution plane of the Moon; (2) plate boundaries are asymmetric, with their geographic polarity being the firstorder controlling parameter; (3) global seismicity depends on latitude and correlates with the decadal oscillations of the excess length of day (LOD); (4) the Earth's 
deceleration supplies energy to plate tectonics, comparable to the computed budget dissipated by the deformation processes; and (5) the GR law supports that the whole lithosphere is a SOC state, i.e. a force is acting contemporaneously on all the plates and distributes the energy over the whole lithospheric shell, which is a condition that can be naturally satisfied by a force acting at the astronomical scale (Riguzzi et al. 2010).

In plate tectonics, it is assumed that the inertia and acceleration of the individual plates are nonexistent or negligible, and thus the plates are in dynamic equilibrium (Forsyth and Uyeda 1975). At present, the solid Earth can be considered in energetic equilibrium; the energy sources that keep its dynamical processes running and the phenomena that consume the majority of terrestrial energy resources are equivalent in magnitude (see the Appendix of Riguzzi et al. 2010). Thus, it is natural to assume that the balance is in quasi-equilibrium, i.e. there is no statistically meaningful difference between the total incoming and outgoing energy rates. This circumstance allows for relatively small energy sources to influence global tectonic processes, and therefore the tidal despinning can contribute to plate tectonics through the westward lithospheric drift (Bostrom 1971; Knopoff and Leeds 1972). Small perturbations in the velocity of rotation trigger the release of large amounts of energy and seismicity (Press and Briggs 1975).

The energy rate, $E$, necessary to move the Earth's shields, i.e. to move the thicker lithosphere relative to the underlying, poorly developed low-velocity channel (as in the Baltic area), has been estimated at about $4 \times 10^{18} \mathrm{~J} / \mathrm{a}$ (Knopoff 1972). A similar value is found by considering the energy of formation of tectonic dislocations, which can be estimated as the rate of energy consumption necessary for lateral displacement of the lithosphere plates relative to the viscous mantle. For a mantle viscosity of $10^{21} \mathrm{~Pa} \cdot \mathrm{s}$, one gets $E=6.5 \times 10^{19} \mathrm{~J} / \mathrm{a}$ (Riguzzi et al. 2010). Recent papers have suggested viscosity values of $10^{17} \mathrm{~Pa} \cdot \mathrm{s}$ (Aoudia et al. 2007; Melini et al. 2008), and consequently, the power needed to move the lithosphere could be significantly lowered, possibly to $E=6.5 \times 10^{15} \mathrm{~J} / \mathrm{a}$. The tidal friction in the Earth-Moon system can be estimated as $E=1.2 \times 10^{20} \mathrm{~J} / \mathrm{a}$ (Riguzzi et al. 2010), and most of this dissipation occurs in the oceans and shallow seas but in only a limited part in the mantle. According to Ray (2001), the tidal dissipation in the mantle amounts to a maximum of $4.2 \times 10^{18} \mathrm{~J} / \mathrm{a}$, whereas the total oceanic and shallow seas dissipation is about $7.5 \times 10^{19} \mathrm{~J} / \mathrm{a}$ (Egbert and Ray 2000). Therefore the residual available power, about $4 \times 10^{19} \mathrm{~J} / \mathrm{a}$, is larger than the value required to move the lithosphere with respect to the mantle, and the Earth's rotation plays a significant role in the generation of the relative shear.
The GR law indicates that large-magnitude earthquakes are very rare events (e.g. Stein and Wysession 2003), and thus the energy released by one large earthquake seems to temporarily deplete the energy budget of plate tectonics, i.e. a slab interaction with the surrounding mantle is not an isolated system but participates in the global expenditure of stored energy. Plate tectonics is an Earth-scale process, and the energy source for its activation is not concentrated in limited zones (e.g., subduction zones). Instead, it acts contemporaneously over the entire lithosphere, as does the Earth's rotation. Romashkova (2009) has recently shown how the Earth's seismicity indicates that the lithosphere can be considered a cohesive unit. Only the global seismicity follows the GR law, and this simple SOC relationship does not hold when considering smaller portions of the Earth (Molchan et al. 1997). Even if not conclusive, these models and supporting evidence are in favor of a significant contribution from the Earth's rotation to plate tectonics.

Mantle convection, widely assumed to be the main cause of plate tectonics, is complemented and polarized by the steady-state torque provided by the tidal bulge misalignment. The horizontal component of the Earth's tide pumps the system, and the vertical component of the tides excites gravity oscillations, which locally load and unload the tectonic features. Low solid tide (larger gravity) favors extensional tectonics, whereas high solid tide (smaller gravity) triggers compressional tectonics. The differential velocity among plates would be controlled by the viscosityrelated variable decoupling at the base of the lithosphere, combined with other forcing mechanisms of mantle convection such as mantle drag and slab pull. Numerical and analog modeling should further test this model. The case of the Earth seems to be not unique: tidal forces on the early lithosphere of Mars from former satellites in retrograde orbits may have pulled the lithosphere in an east-west direction over hot mantle plumes (Kobayashi and Sprenke 2010).

\section{Reliable seismic hazard assessment}

Standard seismic hazard assessment (SHA) techniques rely on the assumption that GR law has global and local (scaleindependent) validity. The global-scale assumption is essentially supported by empirical observations, while the local-scale validity has been proven absolutely unreliable by models and facts (Nekrasova et al. 2011; Molchan et al. 1997; Kossobokov and Nekrasova 2012). In the polarized plate tectonic model, differential velocity among plates is controlled by viscosity variations in the low-velocity layer, generating variable decoupling between lithosphere and mantle. The shortcoming at the local scale is not removed 


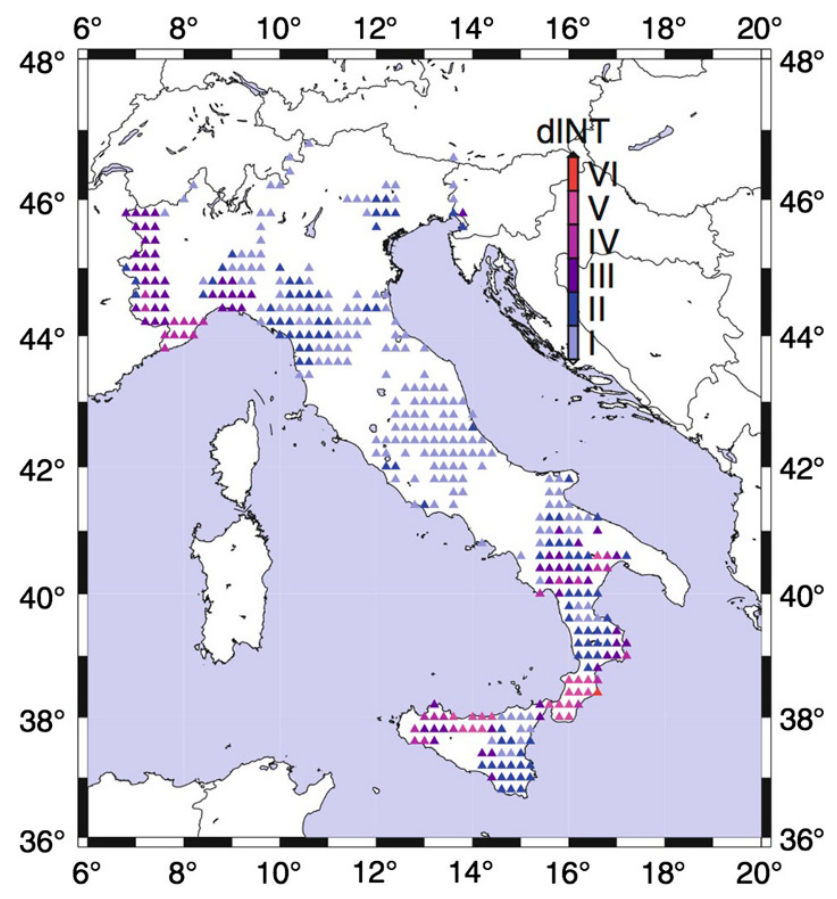

Fig. 5 Seismic hazard in Italy in terms of MCS intensity scale: upward triangles indicate NDSHA > PSHA, and downward triangles indicate NDSHA < PSHA (from Panza et al. 2011)

by polarized plate tectonics, and this is another reason why we developed the neo-deterministic seismic hazard assessment approach (NDSHA) (e.g. Panza et al. 2001, 2012). This neo-deterministic approach is scenario-based and includes the maximum credible earthquake (MCE) method for seismic hazard analysis, where realistic and duly validated synthetic time series-generating a data bank of several thousands of seismograms, accounting for source, propagation, and site effects-are used to construct ground-shaking scenarios. NDSHA integrates the available information provided by seismological, geological, geophysical, and geotechnical databases with advanced physical modeling techniques, to provide a reliable and robust background for the development of a design basis for cultural heritage and civil infrastructures.

\subsection{Why NDSHA has been developed in Italy first and then applied internationally}

Worldwide, Italy is the sole country where a reliable earthquake catalog exists, dating as far back as the year 1,000 at least for events with $M>5$ or $I>$ VII (e.g. Vorobieva and Panza 1993). NDSHA has been developed to take advantage of the uniqueness of the Italian earthquake catalog, while at the same time using the wealth of quantitative geological, structural, and seismotectonic knowledge that is homogeneously available for the entire country
(Panza et al. 2001, 2011, 2012). NDSHA uses all of these data in the framework of a physical model of seismogenesis. Such a model has natural limits that, however, turn out to be less severe than those of the statistical model that is the basis of the standard probabilistic approaches for SHA (PSHA). PSHA estimates the probability that ground motion exceeds some given level. In such a way, potentially useful information is obtained that unfortunately is not sufficiently reliable to define seismic hazard. Characterizing the recurrence of earthquakes using PSHA requires the availability of earthquake catalogs that are complete for relatively low magnitudes $(M \leq 4)$. These catalogs are available for only a very short time interval (since about 1900 in Italy, and not for the entire country). For NDSHA, the knowledge of recurrence is not crucial; it is necessary to know about the earthquakes capable of generating damage, conventionally defined by $M>5$. Therefore, it is possible to use data sets that span relatively longer periods (in Italy, since year 1000). Contrary to what is strictly required by PSHA, NDSHA does not require convolutive methods - thereby reducing a tensor problem (wave generation and propagation) to a scalar one (like the ground motion predictive equations, GMPE) — which have been proven to be unreliable, mostly in geologically complex areas (e.g. Burger et al. 1987; Panza and Suhadolc 1989; Fäh and Panza 1994; Bragato et al. Bragato et al. 2011).

Estimates of seismic hazard obtained using NDSHA and PSHA are compared for the Italian territory (Fig. 5). NDSHA provides values larger than those given by PSHA in areas where large earthquakes are observed and in areas identified as being prone to large earthquakes but provides lower values in low-seismicity areas. These differences suggest the adoption of the flexible, robust, and physically sound NDSHA approach for reliable seismic hazard estimation. NDSHA allows us to overcome the shortcomings of PSHA, including its proven tendency to underestimate ground shaking for the largest earthquakes, especially for those areas characterized by a prolonged quiescence, i.e. in tectonically active sites where events of only moderate size have occurred in historical times (Panza et al. 2011). The case-study of the event in Emilia (Italy) on May 20, 2012 is discussed in detail by Peresan and Panza (2012) and is only briefly illustrated in Fig. 6. In order to exploit the uniqueness of the situation in Italy, a parliamentary bill has been issued to use both PSHA and NDSHA.

NDSHA can be applied with due caution even when the data are not so complete. In such a case, the reliability of the results decreases, though the results are comparable to if not better than what can be obtained, using the same data, with PSHA. When combined with intermediate-term, middlerange earthquake prediction (Peresan et al. 2005), NDSHA can be used to readily produce time-dependent hazard maps (Peresan and Panza 2012) and can be extended to provide 

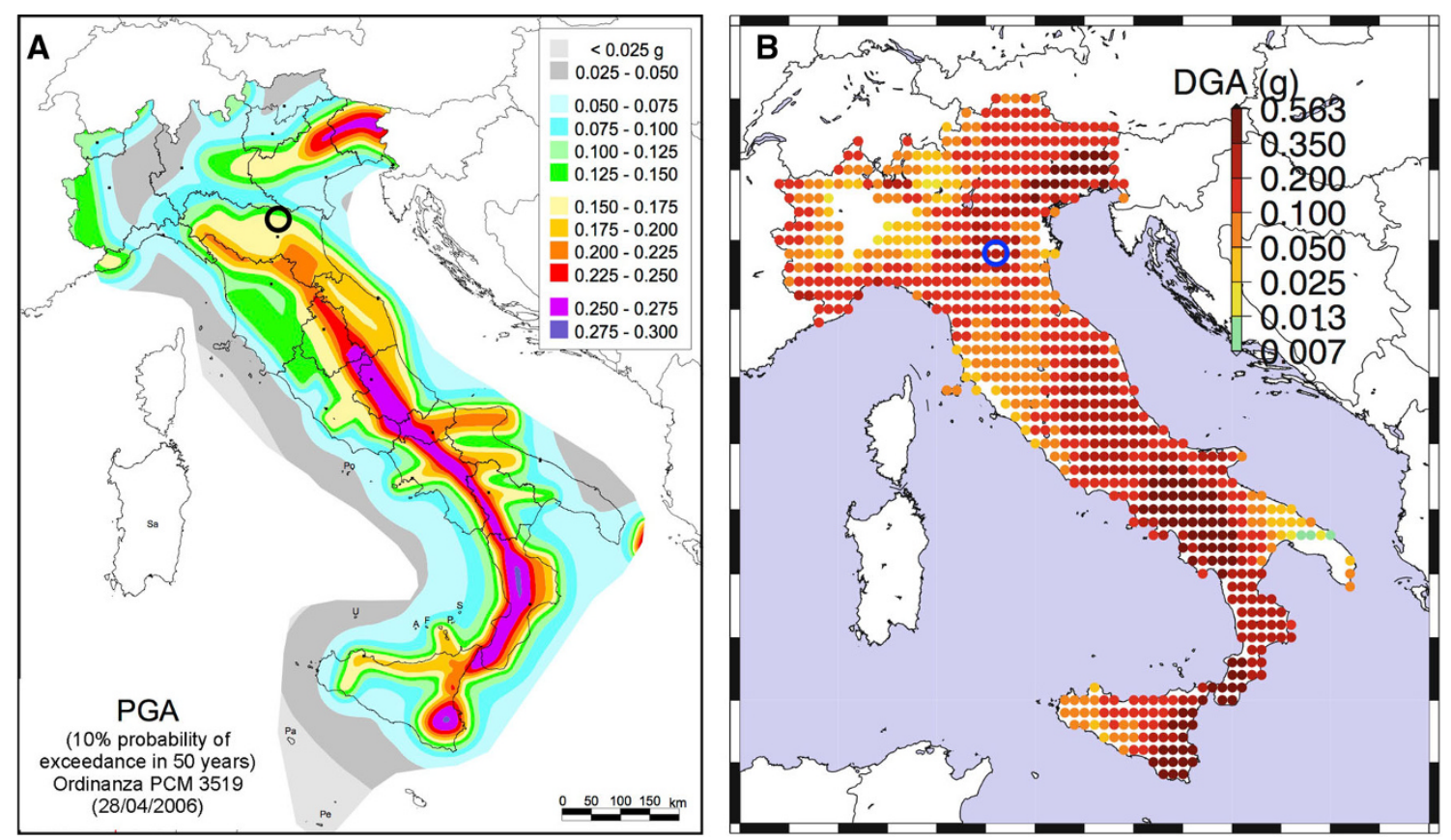

Fig. 6 Seismic hazard maps developed using a PSHA and b NDSHA. The PSHA map is currently the official reference seismic hazard map for Italy. The epicenter of the Emilia earthquake is marked (black dot in (a); blue circle in (b). a Puts the Emilia epicenter in an area expected to have low ground shaking. Contrary to this, $\mathbf{b}$ assesses the seismic hazard in the area near the epicenter to be higher (from Peresan and Panza 2012)

information needed for risk assessment using appropriate statistical models. It is an in-progress study (Ruggieri et al. 2012) in collaboration with research institutions in India (Institute of Seismological Research, Gujarat and Centre for Mathematical Modelling and Computer Simulation, Bangalore), and there are advanced-stage pilot projects in several countries (e.g. Mourabit et al. 2014).

\subsection{3-D modeling of seismic input}

The NDSHA approach can be applied on a regional scale, computing seismograms at the nodes of a grid with the desired spacing, or on a local scale, taking into account the source characteristics, the path, and local geological and geotechnical conditions in three-dimensional (3-D) laterally heterogeneous anelastic models (e.g. Panza et al. 2011, 2012). In fact, it is an acquired result that, in order to enable realistic earthquake hazard assessment and reliable estimation of the ground motion response to an earthquake, three-dimensional velocity models have to be considered.

For the Italian case, Panza et al. (2012) showed the effect of a change in the properties of the structural model on the propagation of the seismic waves generated by the earthquake sources. They used a set of 3-D cellular structures $\left(1 \times 1^{\circ}\right)$ obtained through an optimized non-linear inversion of surface-wave dispersion curves (see Brandmayr et al. 2010 and references therein). The properties of the uppermost layer of the structures, which are relevant for the characteristics of the ground motion observed at the free surface, are quite different from those used in the previous models. These structural models are quite suitable for the construction of geological, geochemical, and geodynamical models (e.g. Brandmayr et al. 2011) but are sometimes locally inadequate for the computation of seismic ground motion scenarios; these areas should be the ones on which to concentrate and properly plan future investigations.

A recent analytical procedure for determining the seismic wave-field in a 3-D anelastic Earth model, with a conventional cutoff at $10 \mathrm{~Hz}$, combines the ray theory with the modal summation method (La Mura et al. 2011). The method has high efficiency, and in fact, once the study region is identified and the 3-D model is constructed, the computation of the three components of the synthetic signal (displacement, velocity, and acceleration) at each station takes, as a rule, a few hours on a $2 \mathrm{GHz} \mathrm{CPU}$, even for distances of a few hundreds of kilometers. Three-dimensional simulations performed for the 1990 Odawara (Fig. 7) and 2003 Bam earthquakes are briefly discussed. For more details, see Gholami et al. $(2012,2013)$ and Panza et al. (2012). 


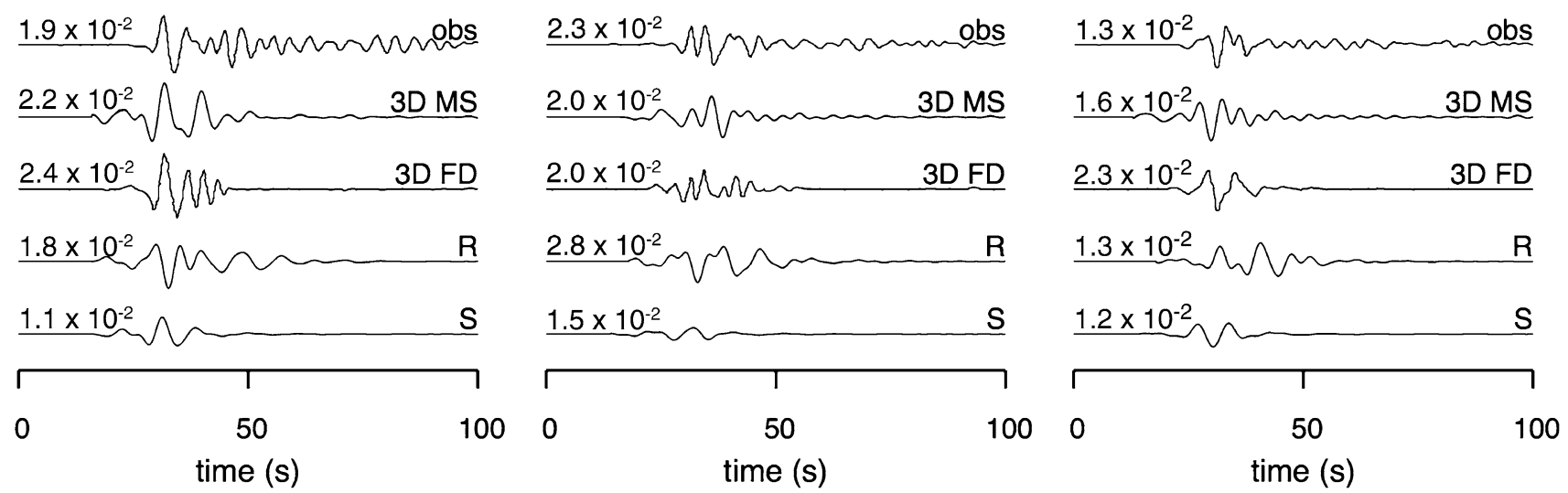

Fig. 7 Comparison of 3-D signals at Fuchinobe station (Japan) between band-pass filtered $(0.1-0.3 \mathrm{~Hz}$ ) displacement data (obs), analytical synthetics (3DMS), numerical synthetics (3DFD), and 1-D synthetic at the station (R); S-trace: 1D simulations for the structure where the source is located. Peak amplitudes in centimeters (from Panza et al. 2012)

\subsubsection{Odawara event}

Comparison of the 3DMS, 3DFD synthetics, and observed data (example of Fuchinobe station shown in Fig. 7) at seven stations selected throughout the Kanto Basin in Japan reveals that the 3DMS synthetics fit the early part of the recorded and 3DFD waveforms; it is clear that the modeling does not reproduce all the details seen in the recorded waveforms for both sets of synthetic signals. These discrepancies are due to a localized shallow velocity structure not modeled in the 3DFD velocity model from which we derived our own model (La Mura et al. 2011).

\subsubsection{Bam event}

The comparison of the observed data with the 3-D synthetic signals, obtained with the 3DMS method, reveals that the synthetics reasonably match the early part of the recorded waveforms, while the details seen in the recorded waveforms, especially at the higher frequencies, are not well reproduced. These discrepancies can be naturally explained by inadequacies in the 3-D structures as explained by Gholami et al. (2013). The 3DMS procedure enables a realistic estimate of seismic hazard in those areas for which scarce (or no) historical or instrumental information is available; it also enables the relevant parametric analyzes to be performed. For instance, different source and structural models can be taken into account to create a wide range of possible ground-shaking scenarios from which to extract essential information for decision-making in prevention and development planning. In conclusion, the level of repeatability of recorded events, using information from literature and not by means of any inversion, supplies data of sufficient quality for practical seismic engineering applications, seismic zonation, and microzonation.

\section{Conclusions}

The International Conference on 3-D Wave Propagation and Imaging through the Earth's Interior held in Wuhan 18-20 May 2013 offered a great opportunity to document the importance of waveform modeling for better understanding the broad range of problems that are affecting our planet.

In particular, the main conclusions of this paper are:

(1) Classical plate tectonics requires revision, and there is accumulating evidence supporting westward mantle drift, i.e., polarized plate tectonics. The reliable assessment of the seismic hazard at global and national scales, seismic zonation, and microzonation are fundamental pieces of information for the correct retrofitting of existing infrastructures and for the development of new ones.

(2) Standard PSHA hazard assessment (e.g. Giardini et al. 2003) is not reliable for many reasons well described in recent literature, and these statistical approaches should be validated by means of physical approaches like NDSHA for the sake of safety.

(3) For a detailed comparison of PSHA and NDSHA performances, see Peresan et al. (2013), who, comparing the standard NDSHA map and the maps of ground motion for a given return period in the Italian region, concluded that the introduction of a return period causes a systematic underestimation of the expected ground motion. When the reference hazard maps for the Italian seismic code, obtained by PSHA, and the ground motion maps, based on NDSHA, are tested against the real seismicity for the territory of Italy, the comparison shows that, as a rule, the predictions provide rather conservative estimates and that the NDSHA maps appear to outscore the PSHA 
ones in terms of efficiency in predicting ground shaking.

(4) Advanced broadband modeling of wave generation and propagation in laterally heterogeneous anelastic media permits the reproduction of the main features of recorded seismograms, directly from available literature information. This possibility offered by direct forward computations is of paramount importance for reliable hazard assessment, via the exploitation of the most powerful computer tools and by means of intensive parametric tests, the only tool that can partly compensate the epistemic uncertainty affecting the data that are relevant for earthquake hazard estimation.

\section{References}

Anderson DL (2002) Plate Tectonics as a far-from-equilibrium selforganized system. In: Stein S, Freymuller J (eds) AGU Monograph: Plate Boundary Zone, Geodynamics Series 30. p 411-425

Anderson DL (2007) New theory of the earth. Cambridge University Press, Cambridge

Aoudia A, Ismail-Zadeh AT, Romanelli F (2007) Buoyancy-driven deformation and contemporary tectonic stress in the lithosphere beneath Central Italy. Terra Nova 19:490-495

Bostrom C (1971) Westward displacement of the lithosphere. Nature 234:536-538

Bragato PL, Sugan M, Augliera P, Massa M, Vuan A, Saraò A (2011) Moho reflection effects in the po plain (Northern Italy) observed from instrumental and intensity data. Bull Seismol Soc Am. doi:10.1785/0120100257

Brandmayr E, Raykova R, Zuri M, Romanelli F, Doglioni C, Panza GF (2010) The lithosphere in Italy: structure and seismicity. J Virtual Explor 36(1):21

Brandmayr E, Marson I, Romanelli F, Panza G.F (2011). Lithosphere density model in Italy: no hint for slab pull. Terra Nova 23: 292-299

Burger W, Sommerville PG, Barker JS, Herrmann RB, Helmberger DV (1987) The effect of crustal structure on strong ground motion attenuation relations in eastern North America. Bull Seism Soc Am 77:1274-1294

Crespi M, Cuffaro M, Doglioni C, Giannone F, Riguzzi F (2007) Space geodesy validation of the global lithospheric flow. Geophys J Int 168:491-506

Doglioni C, Ismail-Zadeh A, Panza G, Riguzzi F (2011) Lithosphereasthenosphere viscosity contrast and decoupling. Phys Earth Planet Inter 189:1-8

Egbert GD, Ray RD (2000) Significant dissipation of tidal energy in the deep ocean inferred from satellite altimeter data. Nature 405:775-778

Fäh D, Panza GF (1994) Realistic modeling of observed seismic motion in complex sedimentary basins. Ann Geofis 37:1771-1797

Forsyth D, Uyeda S (1975) On the relative importance of driving forces of plate motion. Geophys. J. R. Astron. Soc. 43:163-200

Foulger GR (2010) Plates vs. Plumes: A Geological Controversy. Wiley-Blackwell, Hoboken

Foulger G, Panza GF, Artemieva IM, Bastow ID, Cammarano F, Evans JR, Hamilton WB, Julian BR, Lustrino M, Thybo H,
Yanovskaya TB (2013) Caveats on tomographic images. Terra Nova. doi:10.1111/ter.12041

Gholami V, La Mura C, Hamzehloo H, Panza GF (2012) 3-Dimensional modal summation simulation of $2003 M_{\mathrm{w}}=6.6$ bam earthquake South Eastern Iran. In: 15th World Conference on Earthquake Engineering. Lisbon, 24-28 Sept 2012

Gholami V, Hamzehloo H, La Mura C, Ghayamghamian MR, Panza GF (2013) Simulation of selected strong motion records of the $2003 M_{\mathrm{w}}=6.6$ Bam earthquake (SE Iran). Geophys J Int. doi:10.1093/gji/ggt405

Giardini D, Grunthal G, Shedlock KM, Zhang P (2003) The GSHAP Global Seismic Hazard Map. In: Lee W, Kanamori H, Jennings $\mathrm{P}$, Kisslinger C (eds) International Handbook of Earthquake \& Engineering Seismology, International Geophysics Series 81 B. Academic Press, Amsterdam, pp 1233-1239

Jin Z-M, Green HG, Zhou Y (1994) Melt topology in partially molten mantle peridotite during ductile deformation. Nature 372:164-167

Keilis-Borok V, Soloviev A (eds) (2003) Nonlinear Dynamics of the Lithosphere and Earthquake Prediction. Springer Series in Synergetics, XIII, ISBN 978-3-662-05298-3

Kircher A (1678) Mundus Subterraneus in XII libros digestus. Editio tertia, Amsterdam, 1678. Reprint: Vai GB (ed), Arnaldo Forni Publisher, Sala Bolognese, 2004

Knopoff L (1972) Observations and inversion of surface-wave dispersion. Tectonophysics 13:497-519

Knopoff L, Leeds A (1972) Lithospheric momenta and the deceleration of the Earth. Nature 237:93-95

Kobayashi D, Sprenke KF (2010) Lithospheric drift on early Mars: evidence in the magnetic field. Icarus. doi:10.1016/j.icarus.2010. 06.015

Kossobokov VG, Nekrasova AK (2012) Global Seismic Hazard Assessment Program maps are erroneous. Seismic Instruments 48:162-170. doi:10.3103/S0747923912020065

La Mura C, Yanovskaya TB, Romanelli F, Panza GF (2011) Threedimensional seismic wave propagation by modal summation: method and validation. Pure appl Geophys 168:201-216. doi:10. 1007/s00024-010-0165-2

Melini D, Cannelli V, Piersanti A, Spada G (2008) Post-seismic rebound of a spherical Earth: new insights from the application of the Post-Widder inversion formula. Geophys $\mathrm{J}$ Int 174:672-695

Molchan G, Kronrod T, Panza GF (1997) Multi-scale seismicity model for seismic risk. Bull Seismol Soc Am 87:1220-1229

Mourabit T, Abou Elenean KM, Ayadi A, Benouar D, Ben Suleman A, Bezzeghoud M, Cheddadi A, Chourak M, ElGabry MN, Harbi A, Hfaiedh M, Hussein HM, Kacem J, Ksentini A, Jabour N, Magrin A, Maouche S, Meghraoui M, Ousadou F, Panza GF, Peresan A, Romdhane N, Vaccari F, Zuccolo E (2014) Neodeterministic seismic hazard assessment in North Africa. J Seismol 2014(18):301-318

Nekrasova A, Kossobokov V, Peresan A, Aoudia A, Panza GF (2011) A multiscale application of the unified scaling law for earthquakes in the Central Mediterranean area and alpine region. Pure appl Geophys 168:297-327. doi:10.1007/s00024-010-0163-4

O'Driscoll LJ, Humphreys ED, Saucier F (2009) Subduction adjacent to deep continental roots: enhanced negative pressure in the mantle wedge, mountain building and continental motion. Earth Planet Sci Lett 280:61-70

Panza GF, Suhadolc P (1989) Realistic simulation and prediction of strong ground motion. In: Carlomagno GM, Brebbia CA (eds) Computers and Experiments in Stress Analysis. Springer-Verlag, New York, pp 77-98

Panza GF, Romanelli F, Vaccari F (2001) Seismic wave propagation in laterally heterogeneous anelastic media: theory and applications to seismic zonation. Advances in Geophysics, vol 43. Academic Press, New York, pp 1-95 
Panza GF, Doglioni C, Levshin A (2010) Asymmetric ocean basins. Geology 38:59-62

Panza GF, Irikura K, Kouteva M, Peresan A, Wang Z, Saragoni R (eds) (2011) Advanced Seismic Hazard Assessment. PAGEOPH, 168, pp 1-386; part 1, doi: 10.1007/978-3-0348-0040-2; part 2, doi: 10.1007/978-3-0348-0092-1

Panza GF, La Mura C, Peresan A, Romanelli F, Vaccari F (2012) Seismic hazard scenarios as preventive tools for a disaster resilient society. In: Dmowska R (ed) Advances in Geophysics, vol 53. Elsevier, London, pp 93-165. doi:10.1016/B978-0-12380938-4.00003-3

Peresan A, Panza GF (2012) Improving earthquake hazard assessments in Italy: an alternative to "Texas Sharpshooting". EOS 93:538-539

Peresan A, Kossobokov V, Romashkova L, Panza GF (2005) Intermediate-term middle-range earthquake predictions in Italy: a review. Earth Sci Rev 69:97-132

Peresan A, Magrin A, Nekrasova A, Kossobokov VG, Panza GF (2013) Earthquake recurrence and seismic hazard assessment: a comparative analysis over the Italian territory. In: Proceedings of the ERES 2013 Conference. WIT transactions on the built environment, vol 132, pp 23-34. doi: 10.2495/ERES130031, ISSN 1743-3509

Pollitz FF, Bürgmann R, Romanowicz B (1998) Viscosity of oceanic asthenosphere inferred from remote triggering of earthquakes. Science 280:1245-1249. doi:10.1126/science.280.5367.1245

Press F, Briggs P (1975) Chandler Wobble, earthquakes, rotation and geomagnetic changes. Nature 256:270-273

Prigogine I, Stengers I (1984) Order Out of Chaos. Bantam, New York
Ray R (2001) Tidal friction in the earth and ocean, Journées Luxembourgeoises de Géodynamique' JLG 89th, 12-14 Nov, http://www.ecgs.lu/

Riguzzi F, Panza G, Varga P, Doglioni C (2010) Can Earth's rotation and tidal despinning drive plate tectonics. Tectonophysics 484:60-73

Romashkova LL (2009) Global-scale analysis of seismic activity prior to 2004 Sumatra-Andaman mega-earthquake. Tectonophysics 470:329-344. doi:10.1016/j.tecto.2009.02.011

Ruggieri F, Peresan A, Vaccari F, Magrin A, Romanelli F, Panza GF, Cozzini S, Fresa A, Sipos G, Scardaci D, Reale M, Krenek A, Matyska L (2012) VRCs on EGI and regional infrastructures. In: Proceedings of Science-EGI Community Forum 2012/emi second technical conference, Munich, 26-30 Mar 2012, pp 1-19

Scoppola B, Boccaletti D, Bevis M, Carminati E, Doglioni C (2006) The westward drift of the lithosphere: a rotational drag? Bull Geol Soc Am 118(1/2):199-209. doi:10.1029/2004TC001634

Shapiro NM, Ritzwoller MH (2002) Monte-Carlo inversion for a global shear velocity model of the crust and upper mantle. Geophys J Int 151:88-105

Stein S, Wysession M (2003) Introduction to Seismology, Earthquakes, and Earth Structure. Blackwell Publishing, Oxford

Stern RJ (2002) Subduction zones. Rev Geophys 40:1012

Vorobieva IA, Panza GF (1993) Prediction of the occurrence of related strong earthquakes in Italy. Pure appl Geophys 141:25-41

Zhang Z, Teng J, Romanelli F, Braitenberg C, Ding Z, Zhang X, Fang L, Zhang S, Wu J, Deng Y, Ma T, Sun R, Panza GF (2014) Geophysical constraints on the link between cratonization and orogeny: evidence from the Tibetan Plateau and the North China Craton. Earth Sci Rev 130:1-48 